Review Article

\title{
Clinical, Biological, and Imaging Features of Monogenic Alzheimer's Disease
}

\author{
Andrea Pilotto, Alessandro Padovani, and Barbara Borroni \\ Clinica Neurologica, Università degli Studi di Brescia, Pza Spedali Civili, 1-25100 Brescia, Italy \\ Correspondence should be addressed to Barbara Borroni; bborroni@inwind.it
}

Received 25 September 2013; Accepted 4 November 2013

Academic Editor: Benedetta Nacmias

Copyright (C) 2013 Andrea Pilotto et al. This is an open access article distributed under the Creative Commons Attribution License, which permits unrestricted use, distribution, and reproduction in any medium, provided the original work is properly cited.

The discovery of monogenic forms of Alzheimer's Disease (AD) associated with mutations within PSEN1, PSEN2, and $A P P$ genes is giving a big contribution in the understanding of the underpinning mechanisms of this complex disorder. Compared with sporadic form, the phenotype associated with monogenic cases is somewhat broader including behavioural disturbances, epilepsy, myoclonus, and focal presentations. Structural and functional imaging show typical early changes also in presymptomatic monogenic carriers. Amyloid imaging and CSF tau/A $\beta$ ratio may be useful in the differential diagnosis with other neurodegenerative dementias, especially, in early onset cases. However, to date any specific biomarkers of different monogenic cases have been identified. Thus, in clinical practice, the early identification is often difficult, but the copresence of different elements could help in recognition. This review will focus on the clinical and instrumental markers useful for the very early identification of AD monogenic cases, pivotal in the development, and evaluation of disease-modifying therapy.

\section{Introduction}

Between 1991 and 1995 different families of early onset Alzheimer's Disease (EOAD) have been linked to mutations within Presenilin (PSEN1, PSEN2) and Amyloid Precursor Protein $(A P P)$ genes [1-3]. The discovery of monogenic forms of Alzheimer's Disease (AD) has allowed improved knowledge of the physiopathology which, in turn, has allowed the design of new therapeutic strategies. After 20 years of basic and clinical research, understanding the early phases of monogenic $\mathrm{AD}$ has become pivotal in order to develop and test the efficacy of the newest target-therapeutic approaches [4].

Even though most monogenic forms of $\mathrm{AD}$ have been described in familial early onset $\mathrm{AD}$, recent findings suggest a wider spectrum of clinical presentation, including late-onset and sporadic forms. Indeed, monogenic AD might present a wide body of clinical symptoms beyond memory deficits, and the careful characterisation is key for a proper diagnosis in unclear cases.

The present review will focus on the clinical and instrumental markers that should be considered in the identification of different forms of monogenic AD.

\section{Epidemiology}

The incidence and distribution of different forms of early onset (or presenile, $<65$ years) dementia (EOD) are still the theme of controversy [5-7]. When considering neurodegenerative conditions, most of the studies showed $\mathrm{AD}$ as the most common aetiology in EOD [5, 7-10], although recent findings indicate that frontotemporal lobar degeneration (FTLD) may have a similar or even higher incidence at this age [11]. Also the relative contribution of PSEN1, PSEN2, and $A P P$ mutations to early onset Alzheimer's Disease (EOAD) is the subject of considerable controversy, and mutation frequency is highly dependent upon the studied population [12-15].

PSEN1 mutations are considered as the major cause of familial AD, accounting for 18 to $55 \%$ of families ([12-14], http://www.molgen.ua.ac.be). The second most common monogenic form of Alzheimer's Disease involves APP mutations and duplication, accounting for $2-18 \%$ and $8 \%$ of autosomal dominant early onset cases, respectively [12, 14, 16-18]. PSEN2 mutations are rare, with only 22 families reported so far (http://www.molgen.ua.ac.be). 


\section{Genes and Pathophysiology of Monogenic AD}

Monogenic AD shares neuropathology features with sporadic AD. Neuronal and synapse loss, extracellular plaques composed of amyloid- $\beta(\mathrm{A} \beta)$ peptides, and intraneuronal neurofibrillary tangles consisting of hyperphosphorylated tau protein [19] are the specific features of the disease [20]. All mutations in Presenilins and APP genes lead to increased amyloidogenic processing of APP, causing the deposition of $\mathrm{A} \beta$ peptide, the primary component of amyloid plaques deposition $[19,21]$. The APP gene has 18 exons and encodes an alternatively spliced transcript that, in its longest isoform, expresses a single transmembrane spanning polypeptide of 770 amino acids that is subject to at least two independent proteolytic pathways. The bulk of APP is cleaved by $\alpha$-secretase within the $\mathrm{A} \beta$-domain to produce a $\mathrm{C}$ terminal fragment, which can be further cleaved intramembranously by $\gamma$-secretase to produce the peptide P3 and the transcriptionally active APP intracellular domain [22]. Alternatively, APP can be sequentially cleaved to produce $\mathrm{A} \beta$ peptide, which requires initial cleavage of APP by $\beta$ secretase, followed by $\gamma$-secretase cleavage [23] within the single-transmembrane domain. If cleavage occurs at residue $712-713$, the most common short $A \beta(A \beta 1-40)$ results; if it is after residue 714, the longer $\mathrm{A} \beta 42$ is generated [24]. $\mathrm{A} \beta 1$ 42 has a higher propensity to form aggregates and has been associated with $\mathrm{AD}$ pathology as component of extracellular amyloid plaques $[19,25,26]$. Presenilins with nicastrin, aph1 , and pen 2 are required for the stability and activity of the $\gamma$-secretase complex [27].

3.1. APP Mutations. Interestingly, most of $A P P$ mutations are located at the $\gamma$-secretase cleavage sites or the APP transmembrane domain on exons 16 and 17, influencing APP processing. The substitutions near the proteolytic sites lead to an overproduction of total amyloid- $\beta$ or a shift in the $A \beta 1$ $40 / A \beta 1-42$ ratio towards formation of the more toxic $A \beta 1$ 42 peptide. The substitutions within the APP transmembrane domain result in formation of amyloid- $\beta$ with increased propensity for aggregation [26]. In addition to more frequent dominant $A P P$ mutations, two recessive mutations causing disease only in the homozygous state were identified: a trinucleotide deletion E693D segregating in one Japanese family proportionally decreased $\mathrm{A} \beta 40$ and $\mathrm{A} \beta 42$ with no change in their ratio [25] and $\mathrm{A} 673 \mathrm{~V}$ in one other Italian family [28]. Additionally, the mutation spectrum extended to $A P P$ locus duplications underscoring the importance of $A P P$ gene dosage in $\mathrm{AD}$, already observed in the case of Down syndrome [29]. Duplicated $A P P$ regions containing several genes $[16,30]$ or $A P P$ only [17] have been clinically linked to early-onset $\mathrm{AD}$ often with extensive cerebral amyloid angiopathy [31].

The mutation A673T within APP was found to be protective against $\mathrm{AD}$ and age-related cognitive decline in a study in Iceland with the evidence of a $40 \%$ reduction in the formation of amyloidogenic peptides in vitro [32]. These findings are not completely understood, given the homozygous presence of the same A673Tsubstitution in a very early onset $\mathrm{AD}$ in a single Italian family [28]. On the other side, Jonnson and colleagues identified three homozygous carriers of A673T in Icelandic samples, one of whom had died at age of 88 , whereas the other two were currently living at age of 67 and 83, respectively, and none had a history of dementia [32].

3.2. PSEN1 and PSEN2 Mutations. PSENs are functionally involved in the $\gamma$-secretase-mediated proteolytic cleavage of APP [21]. Thus, mutations in PSENs result in an increased $\mathrm{A} \beta 42 / \mathrm{A} \beta 40$ ratio, by either an increase in $\mathrm{A} \beta 42$ as shown in plasma and fibroblast media of PSEN mutation carriers [33] or by a decrease in A $\beta 40$, suggesting a loss-of-function mechanism rather than a gain-of-function [34, 35]. PSEN1 and PSEN2 have important sequence homology also at the protein level [2].

PSEN1 gene consists of 12 exons that encode a 467-amino acid protein that is predicted to traverse the membrane six to ten times. The amino and carboxyl terminal are both oriented toward the cytoplasm. The majority of PSEN1 mutations are single-nucleotide substitutions, but small deletions and insertions have been described as well. At present, more than 200 different AD-related mutations have been identified, scattered over the protein with some clustering within the transmembrane domains and the hydrophilic loops surrounding these domains $[13,36,37]$.

PSEN2 has 12 exons and is organized into ten translated exons that encode a 448-amino acid protein. The PSEN2 protein is predicted to consist of nine transmembrane domains and a large loop structure between the sixth and seventh domain and also displays tissue-specific alternative splicing [38]. The mechanism by which PSEN2 increases $A \beta$ generation in the brains of $\mathrm{AD}$ patients remains to be clarified. A recent study found that mutant PSEN2 increases $\beta$ secretase activity through reactive oxygen species-dependent activation of extracellular signal regulated kinase [39].

\section{Clinical Features of Monogenic AD}

In broad terms, the clinical presentation of monogenic $\mathrm{AD}$ is similar to that of sporadic AD. However, the phenotype associated with monogenic $\mathrm{AD}$ is somewhat broader than what is typically seen in sporadic AD. Moreover, neurologic signs and symptoms appear to be more common in monogenic $\mathrm{AD}$ as compared to sporadic forms. The copresence of different elements could help in recognition in clinical practice [37].

4.1. Age at Onset and Survival. Overall, monogenic AD usually has an earlier age at disease onset. The youngest age at onset has been described for PSEN1 mutations; symptoms typically first appear between the age of 30 and 50, but some mutations have been associated with earlier onset [40]. PSEN1 mutations show almost complete penetrance by the age of 60 , with some exceptions (Table 1). The causes of variability of age at onset are neither clear nor completely explained by genetic factors $[41,42]$ or by the biochemical abnormalities of $\mathrm{A} \beta$ ratio due to the mutations [34]. APP pedigrees tend to have an older age at onset, typically in the 50s and ranging 
TABLE 1: Atypical presentation of different PSEN1, PSEN2, and APP mutations.

\begin{tabular}{|c|c|c|c|}
\hline Clinical phenotype & & Mutations & Differential diagnosis \\
\hline $\begin{array}{l}\text { Very early onset } \\
(<30 \mathrm{y})\end{array}$ & PSEN1 & $\begin{array}{l}\text { L85P P117L P117S L166P S169L M233L M233V L235P Y256S V272A } \\
\text { A434C P436Q G206V }\end{array}$ & $\begin{array}{l}\text { GE, MD, SD, PWMD, } \\
\text { HD }\end{array}$ \\
\hline \multirow[t]{2}{*}{ Late onset $(>65 \mathrm{y})$} & PSEN1 & $\begin{array}{l}\text { Uncommon, A79V M139V I143F H163R H163Y A231V K239N L271V } \\
\text { E273A R377W C410Y }\end{array}$ & \multirow[t]{2}{*}{$\begin{array}{l}\text { Sporadic AD, FTD, } \\
\text { LBD, VaD, CJD }\end{array}$} \\
\hline & PSEN2 & Possible for all mutations, especially, M239I and M239V & \\
\hline \multirow[t]{3}{*}{$\begin{array}{l}\text { Behavioral or } \\
\text { psychiatric symptoms }\end{array}$} & PSEN1 & $\begin{array}{l}\text { Common at presentation V89L C92S P117L M139V M146I M146L } \\
\text { H163R H163Y L166P L166R S169L F176L E184D I202F G206A G206V } \\
\text { K239N L250S L250V Y256S R269G R269H V272A E280A L282VA9 } \\
\text { R377W L392P C410Y L424P A434C }\end{array}$ & \multirow{4}{*}{$\begin{array}{l}\text { bvFTD, LBD, HD, } \\
\text { WE, CJD }\end{array}$} \\
\hline & PSEN2 & $\begin{array}{l}\text { Possible at presentation R71W A85V T122P T122R Y231C M239V } \\
\text { M239I }\end{array}$ & \\
\hline & $A P P$ & Rare at presentation D694N A713T & \\
\hline $\begin{array}{l}\text { "Pure" } \\
\text { frontotemporal } \\
\text { presentation }\end{array}$ & PSEN1 & $\begin{array}{l}\text { L113P P117R M139V M146V L174R G183V L226F M233L M233T } \\
\text { P264V E280A V412I L424H }\end{array}$ & \\
\hline \multirow[t]{2}{*}{ Prominent aphasia } & PSEN1 & $\begin{array}{l}\text { E120D H163R H163Y L166R G209V L226F L235R A246E L250S } \\
\text { A260V L262F P264L R278I E280A R377W L392V A431E A434C } \\
\text { L435F }\end{array}$ & \multirow{2}{*}{$\begin{array}{l}\text { Sporadic PPA (svPPA, } \\
\text { lvPPA, avPPA) } \\
\text { FTD-MND, CJD }\end{array}$} \\
\hline & PSEN2 & Y231C & \\
\hline \multirow[t]{3}{*}{ Epileptic seizures } & PSEN1 & $\begin{array}{l}\text { Possible as first presentation; L113P L113Q intron4insTAC P117L } \\
\text { E120D E120G N135S M139I M139V I143T M146I M146L H163P H163R } \\
\text { H163Y L166R S169L S169P S170F E184D G206D G206V Q222H } \\
\text { M233T M233V F237I A246E L250V A260V P264L R269G R269H } \\
\text { E280A E280G L282R L282V L282V A9 R377W L392V L420R L424P } \\
\text { A434C }\end{array}$ & \multirow[t]{3}{*}{$\mathrm{GE}, \mathrm{SD}, \mathrm{MD}, \mathrm{AE}, \mathrm{CJD}$} \\
\hline & PSEN2 & Rare at presentation, often seen during disease course M239V & \\
\hline & $A P P$ & $\begin{array}{l}\text { Possible at presentation for D694N APP duplication (related or not to } \\
\text { ICH) }\end{array}$ & \\
\hline Myoclonus & PSEN1 & $\begin{array}{l}\text { L113P 4insTAC P117R M139V I143T M146L M146I M146V L153V } \\
\text { H163R H163Y S169P S169L L174M E184D G209V Q222H F237I } \\
\text { L250V L250S A260V P264L R269H R269G E280A L286V L392V } \\
\text { C410Y A434C }\end{array}$ & \multirow{3}{*}{$\begin{array}{l}\text { CBS, LBD, PSP, FTD, } \\
\text { CJD }\end{array}$} \\
\hline \multirow[t]{2}{*}{$\begin{array}{l}\text { Parkinsonism, } \\
\text { dystonia, or apraxia }\end{array}$} & PSEN1 & $\begin{array}{l}\text { C92S F105L L113P P117R E120D N135D M139V M146I M146L M146V } \\
\text { H163P H163R H163Y L166R S170F E184D I202F G206A G209V } \\
\text { G217D M233L M233T M233V F237I L250S Y256S G266S V272A } \\
\text { R278I E280A P284L L286V } 9 \text { L381V L392V C410Y A431E L435F } \\
\Delta \text { T440 }\end{array}$ & \\
\hline & PSEN2 & Rare at presentation, possible during disease course A85V M239V & \\
\hline Spastic paraparesis & PSEN1 & $\begin{array}{l}\text { AI83/M84, L85P N135S Y154N InsF1 L166P G217D F237I V261F } \\
\text { V261L P264L P264V G266S L271V R278K R278S R278T E280G } \\
\text { E280Q P284L P284S L286R } \Delta 9 \text { Ins18 T291P L381V, N405S L424R } \\
\text { P436Q }\end{array}$ & $\begin{array}{l}\text { HSP, VaD, PWMD, } \\
\text { MND, CJD }\end{array}$ \\
\hline Cerebellar ataxia & PSEN1 & $\begin{array}{l}\text { P117A N135S M139V I143T H163P L166P S169L S170F Y256S E280A } \\
\text { L282V P436Q }\end{array}$ & $\begin{array}{l}\text { CJD, SCA, MSA-C, } \\
\text { PNS }\end{array}$ \\
\hline Leukoencephalopathy & $A P P$ & D694N A713T & VaD, PWMD, DD, V \\
\hline \multirow{3}{*}{$\begin{array}{l}\text { CAA with or without } \\
\text { ICH }\end{array}$} & PSEN1 & $\begin{array}{l}\text { Rare } \Delta \mathrm{E} 4 \text { V89L 4insTAC E184D C217D L271V V272A E280G L282V } \\
\text { S290C N405S } \Delta \text { T440 }\end{array}$ & \multirow{3}{*}{$\begin{array}{l}\text { Sporadic CAA, } \\
\text { monogenic CAA } \\
\text { (CYST C, TTR, } \\
\text { ITM2B, PRNP } \\
\text { mutations) }\end{array}$} \\
\hline & PSEN2 & Rare R71V N141I & \\
\hline & $A P P$ & $\begin{array}{l}\text { Often present also without cognitive impairment A692G E693Q } \\
\text { E693G E693K D694N A713T APP duplication }\end{array}$ & \\
\hline
\end{tabular}

Abbreviations: AD: Alzheimer's Disease, AE: autoimmune encephalitis, APP: Amyloid Precursor Protein gene, avPPA: agrammatic variant of primary progressive aphasia, bvFTD: behavioural variant of frontotemporal dementia, CAA: cerebral amyloid angiopathy, CBS: corticobasal syndrome, CJD: Creutzfeldt-Jacob Disease, CYST C: Cystatin C gene, DD: demyelinating Disease, FTD: frontotemporal dementia, GE: genetic epilepsy HD: Huntington's Disease, HSP: hereditary spastic paraplegia, ITM2B: integral membrane protein 2B gene, LBD: Lewy Bodies Dementia, lvPPA: logopenic variant of primary progressive aphasia, MD: Mitochondrial Disease, MND: Motor-neuron Disease, MSA-C: cerebellar form of multisystem atrophy, PNS: paraneoplastic syndromes, PRNP: prion protein gene, PSEN1: Presenilin 1 gene, PSEN2: Presenilin 2 gene, PSP: progressive supranuclear palsy, PWMD: progressive white matter disease, SCA: spino cerebellar ataxia, SD: storage disorders, svPPA: semantic variant of primary progressive Aphasia, TTR: Transthyretin gene, VaD: Vascular dementia, V: Vasculitis, WE: Wernicke encephalopathy. 
from 45 to 60 years old. The rarer PSEN2 mutations have the widest range of onset with some late-onset cases [43], and the incomplete penetrance has been postulated.

Overall survival in monogenic AD is similar to sporadic disease with an average of 6-9 years from diagnosis, with the caveat that survival in elderly sporadic individuals tends to be lower. The different age at onset does not influence the disease duration, and, in general, PSEN1 mutation carriers may have slightly shorter survival.

4.2. Cognitive and Behavioural Picture. The majority of monogenic cases have an amnestic presentation very similar to that seen in sporadic disease $[44,45]$. Longitudinal studies of unaffected at-risk individuals have suggested that the earliest neuropsychometric findings involve a fall in verbal memory $[46,47]$, with relatively preserved naming and object perception compared with sporadic AD [44, 45]. However, only few studies conducted a standardised neuropsychological assessment, and atypical cases with subcortical, or aphasic presentation are often reported in the literature [4850]. Atypical language presentation has been associated with specific PSEN1 mutations but is relatively rare in PSEN2 and $A P P$ cases (see Table 1 ).

Recent findings also suggest the possibility of "pure" frontotemporal presentation associated with frontotemporal atrophy or hypoperfusion $[51,52]$. The presence of epileptic seizure very rare in FTLD spectrum and the CSF AD typical biomarkers may help in the differential diagnosis $[51,53]$.

Behavioral and psychiatric symptoms (BPSD) such as delusions, hallucinations, and apathy, often present in sporadic $\mathrm{AD}$, could appear also in monogenic cases. In the largest kindred of monogenic AD studied in the PSEN1E280A population from Antioquia, memory impairment was detected in $100 \%$ of cases, and behavioural changes were present in $94 \%$ of individuals [54].

4.3. Myoclonus and Seizures. In monogenic AD, the frequency of myoclonus increases with the duration of illness. All monogenic AD forms have been associated with the presence of myoclonus, and some PSEN1 variations have been linked to the early presentation of this sign. Several reports also suggest myoclonus as a harbinger of the more common seizures.

Seizures could represent the first presentation in many cases of monogenic AD, especially, for PSEN1 mutations. In clinical practice, in early-onset cases, it could be difficult to differentiate autosomal dominant $\mathrm{AD}$ from genetic epilepsy or storage disorder such as neuronal ceroidlipofuscinosis [55]. Some PSEN1 mutations have been identified in cases with prominent epilepsy at presentation (see Table 1). Seizures are very common in APP duplication and Down syndrome that have an extra copy of $A P P$, thus reflecting a possible link between $\mathrm{A} \beta$ dosage and epilepsy [56]. It has been shown in experimental animals that amyloid $\beta$ peptides may induce neuronal hyperexcitability and trigger progressive epilepsy [57]. Myoclonus and seizures have not been reported in a few PSEN1, PSEN2, and APP mutations, but this absence may simply reflects restricted duration of follow-up.

4.4. Other Neurological-Associated Signs or Symptoms. PSEN1 phenotypes also include extrapyramidal, pyramidal, or cerebellar isolated presentation, rarer in PSEN2 or APP-mutated patients (Table 1). However, prominent parkinsonism associated with dementia and visual hallucinations fulfilling diagnostic criteria for Lewy Body Dementia (LBD) have been only rarely associated with PSEN1 and PSEN2 mutations [40, 58, 59].

Spastic paraparesis associated with memory complains has been also associated with certain PSEN1 mutations [60]. The neuropathological correlate is often the presence of "cotton wool plaques", consisting of A $\beta$ deposits with a lack of amyloid in the core and poor neuritic and glial response [61].

Cerebellar ataxia or gaze-evoked nystagmus has been only noted occasionally in PSEN1 mutations carriers. In PSEN2 and APP cases, pyramidal or cerebellar neurological signs could be present but not representing the onset symptom.

4.5. Intracerebral Hemorrhages and Cerebral Amyloid Angiopathy. Cerebral amyloid angiopath (CAA) is a generic morphological term describing the pathological changes occurring in cerebral blood vessels resulting from deposition of amyloid proteins of different origins. The most severe clinical consequence of CAA is cerebral haemorrhage, and according to autopsy series, 12 to $25 \%$ of all cerebral haemorrhages in the elderly are due to CAA $[62,63]$.

The first mutation described in the APP gene was found within the $A \beta$ region in a family with autosomal form of CAA [64]. In this condition, cerebral haemorrhage was fatal in about two thirds of patients, whilst the one third developed multiple strokes resulting in dementia of vascular type [65]. In 2006, the duplication of APP was also associated with a clinical phenotype characterised by a progressive dementia of AD type associated with CAA [17, 30, 31]. Substitution and duplication of APP gene have been also associated with variable white matter abnormalities up to severe leukoencephalopathy.

If CAA and cerebral haemorrhage are the key features of $A P P$ monogenic $\mathrm{AD}$, their presence is only rarely associated with PSEN1 or PSEN2 phenotypes (Table 1).

\section{Neuroimaging Features of Monogenic AD}

It is well established that in sporadic $\mathrm{AD}$ the brain regions early and more severely affected are the medial temporal lobes, especially, the hippocampus and entorhinal cortex, the posterior portion of the cingulate gyrus, and the precuneus $[66,67]$. In monogenic $\mathrm{AD}$, several reports showed a similar atrophy pattern with a slight more severe medial-temporal lobe atrophy compared with sporadic AD [68]. Gray matter regional volume loss and decreases in magnetization transfer ratio have also been reported in mildly symptomatic carriers [69]. Additionally, it has been well established that in early 
onset $\mathrm{AD}$, hippocampus may be not always involved as in the typical form and that frontoparietal areas showed greater atrophy in monogenic forms compared with sporadic late onset cases $[68,70,71]$. APP mutations seem to be more associated with hippocampal atrophy, whereas PSEN1 mutation carriers had more general neocortical involvement and a prominent frontotemporal atrophy $[68,72]$. However, given the high heterogeneity of phenotype-genotype correlation in monogenic $\mathrm{AD}$, it would be difficult to find a definitive structural biomarker specific and different for PSEN1, PSEN2, or APP.

Interestingly, as previously reported, certain mutations within APP genes presented leukoencephalopathy that should be evaluated on MRI in order to exclude a possible influence of white matter lesions on cognitive decline [73]. In suspected cerebral amyloid angiopathy, an MRI with gradient echo sequences should be performed to show the presence of cerebral microbleeds (or microhaemorrhages), visualized as small, rounded, dot-like lesions of low signal intensity in the $\mathrm{T} 2{ }^{*}$-weighted images [74]. Susceptibility-weighted imaging has considerably increased microbleed detection rates compared with gradient echo sequences [75] although the sensitivity to detect microbleeds is also dependent on slice thickness and magnetic field strength. Microbleeds in deep brain regions are most likely to be associated with vasculopathy owing to hypertension, whilst their distribution is mostly lobar in specific disorders such as sporadic cerebral amyloid angiopathy [76].

In atypical monogenic $\mathrm{AD}$ phenotypes, such as epileptic, paraparetic, or ataxic variants, MRI is also essential to distinguish AD from storage or mitochondrial disorders [77], Creutzfeldt-Jacob Disease (CJD) [78], or other specific forms [79].

Along with structural imaging, cerebral blood flow SPECT (single-photon emission computer tomography) and brain FDG-PET (fludeoxyglucose Positron emission tomography) scans in monogenic $\mathrm{AD}$ patients show predominant hypoperfusion or reduced glucose metabolism in the temporoparietal regions, including the precuneus and the posterior cingulate cortex, a pattern similar of sporadic AD [80]. However, as outlined in the clinical section, many autosomal dominant cases showed an extended phenotype involving also frontal and prefrontal areas, and cases with pure frontotemporal hypoperfusion pattern have been reported [51, 52].

Only few studies compared the ability of SPECT and FDG-PET to discriminate AD from other dementia. FDGPET revealed to have higher sensitivity and specificity if compared to SPECT $[81,82]$. In atypical focal monogenic AD functional neuroimaging reflects the topographical distribution of neurodegeneration and not the underlying pathology. Thus the role of SPECT and FDG-PET is still controversial.

5.1. Amyloid Imaging. More recently, PET amyloid imaging studies with Pittsburgh Compound $\mathrm{B}(\mathrm{PiB})$ have revealed evidence of fibrillar $\mathrm{A} \beta$ deposition in monogenic $\mathrm{AD}$, including carriers who were up to 10 years younger than the age of onset for their family [83]. Interestingly, these studies have consistently reported elevated levels of $\mathrm{PiB}$ retention in the striatum of presymptomatic monogenic $\mathrm{AD}$ individuals, which occurs more variably in late-onset sporadic AD [47].

Amyloid imaging such as 11C-PIB PET has very high (90\% or greater) sensitivity for AD although the specificity decreases with aging [84]. The amyloid imaging tracers flutemetamol, florbetapir, and florbetaben labelled with $18 \mathrm{~F}$ demonstrated good accuracy for distinguishing patients with $\mathrm{AD}$ from other tauopathies or TDP-43 pathologies $[83,85-$ 87]. Amyloid tracer binding is diffuse and symmetrical, with high uptake consistently found in the prefrontal cortex, precuneus, and posterior cingulate cortex, followed by the lateral parietal, lateral temporalcortex, and striatum.

Another important role of amyloid imaging will be the differential diagnosis of intracranial haemorrhage caused by small vessel disease or cerebral amyloid angiopathy, the last showing positive scans.

\section{Cerebrospinal Fluid and Blood Biomarkers}

In the assessment of a presenile or atypical dementia, cerebrospinal fluid (CSF) should be performed in order to exclude other mimicking diseases. In monogenic $\mathrm{AD}$, multiple groups have reported that CSF $\mathrm{A} \beta 42$ is reduced to approximately one-half of normal values [88], a finding remarkably similar to sporadic $\mathrm{AD}$ [89]. While decreased $\mathrm{A} \beta 42$ appears to have remarkable specificity for pathologic $\mathrm{AD}$ and $\mathrm{A} \beta$ amyloidosis in the brain [90], CSF $\mathrm{A} \beta 40$ is not consistently different in $\mathrm{AD}$ individuals compared with normal individuals. However some PSEN1 mutations have been also associated with increased $\mathrm{A} \beta 42$ production reflected also in CSF, thus altering the paradigm of a low $\mathrm{A} \beta 42$ in all $\mathrm{AD}$ forms [91]. CSF tau and phosphotau levels are increased almost two-fold in monogenic $\mathrm{AD}$ individuals compared with controls [88], again mimicking the CSF profile in later onset sporadic $\mathrm{AD}$.

In clinical practice, CSF Tau/A $\beta 42$ ratio may reflect the underlying pathology also in focal atypical presentation such as corticobasal degeneration [92], bvFTD [53] or primary progressive aphasia [93]. As for amyloid imaging, in earlyonset cases in which a copathology with $\mathrm{AD}$ is very rare, CSF analysis should be performed, and it has a higher specificity value.

Increased plasma $\mathrm{A} \beta 42$ has been consistently found in monogenic $\mathrm{AD}[47,91]$, while there is little, if any, consistently reported difference in sporadic $\mathrm{AD}$ [94].

The use of new genetic detecting methods, such as next generation sequencing, will probably change the scenario of presenile dementia genetics. A recent screening for 16 different dementia disease genes proposed by Beck et al. [95] at UCL showed a great sensitivity (82\%) and specificity (100\%) in detecting pathogenic alterations compared with normal methods. Interestingly, APP duplication could be missed also with these new approaches, underlying the importance of a right clinical selection of these cases [95].

Gene expression analysis in monogenic forms may also help in the identification of early serum biomarkers [96], as already demonstrated for other forms of dementia [97]. 


\section{Presymptomatic at-Risk Subjects}

Several series of presymptomatic mutation carriers have been studied in order to elucidate the very early phases of monogenic AD. Owing to the geographically dispersed nature of monogenic $\mathrm{AD}$ families and the relative rarity of the disease, an international network of research centres has been established, formally known as the Dominantly Inherited Alzheimer's Network [DIAN]. In 2012, the first DIAN report confirmed that changes begin in the brain about 25 years before expected symptom onset with the decline in $\mathrm{A} \beta 42$ concentrations in the CSF in mutation carriers, as compared with noncarriers [47]. A $\beta 42$ deposition as measured by PIBPET was detected at least 15 years before expected symptom onset [98]. Increases in levels of tau in the CSF and in brain atrophy were detected approximately 15 years before expected symptom onset, followed by cerebral hypometabolism and impaired episodic memory approximately 10 years before expected symptom onset and global cognitive impairment starting at 5 years before expected symptom onset.

Longitudinal structural imaging studies have demonstrated alterations in white matter structure in presymptomatic and early symptomatic carriers, with decreased fractional anisotropy in the fornix and widespread areas of brain visualized with diffusion tensor imaging [99]. Several neuroimaging studies showed that even before the bilateral hippocampal atrophy, presymptomatic mutation carriers have an increase caudate size [100] and early thalamus involvement [101]. The grey matter atrophy may be not restricted to hippocampus but also to other cortical areas, especially, precuneus, parietal, or frontal brain regions [71,102]. A recent DIAN study on more than 100 presymptomatic and symptomatic carriers confirmed the early thalamus involvement and showed white matter atrophy in the cingulum and fornix [103]. Functional connectivity has also recently showed the early disruption of the default mode network in monogenic $\mathrm{AD}$ even before the symptoms presentations [104].

\section{Conclusions}

The wide spectrum of presentation of monogenic AD leads often to late diagnosis or missidentification of cases.

The memory impairment, still essential for the new revised research criteria in association with CSF or imaging biomarkers for the diagnosis of $\mathrm{AD}$ [105], is not always the prominent early deficit. Behavioural disturbances, epilepsy, myoclonus, or CAA (specific for APP mutations) may help in addressing diagnosis. However, structural or functional neuroimaging is more consistent with focal phenotypes than the AD pathology. Thus, CSF or amyloid imaging may be useful in the differential diagnosis with other neurodegenerative dementias, especially in early onset cases, but these biomarkers cannot be considered specific for the different involved genes.

In cases suggestive for autosomal dominant $\mathrm{AD}$, we suggested a screening of PSEN1 mutation first, followed by $A P P$ and PSEN2 mutations on the basis of epidemiological data, but new specific biomarkers driving genetic screening are warranted. Since more than 20 years, the study of familial forms is giving a big contribution in the understanding of the underpinning mechanisms of $\mathrm{AD}$ and possible target approaches. Thus, a very early identification of monogenic cases is pivotal in the development and evaluation of diseasemodifying therapy needed also in the most common sporadic form.

\section{Conflict of Interests}

The authors declare that there is no conflict of interests regarding the publication of this paper.

\section{References}

[1] A. Goate, M.-C. Chartier-Harlin, M. Mullan et al., "Segregation of a missense mutation in the amyloid precursor protein gene with familial Alzheimer's disease," Nature, vol. 349, no. 6311, pp. 704-706, 1991.

[2] E. I. Rogaev, R. Sherrington, E. A. Rogaeva et al., "Familial Alzheimer's disease in kindreds with missense mutations in a gene on chromosome 1 related to the Alzheimer's disease type 3 gene," Nature, vol. 376, no. 6543, pp. 775-778, 1995.

[3] R. Sherrington, E. I. Rogaev, Y. Liang et al., "Cloning of a gene bearing missense mutations in early-onset familial Alzheimer's disease," Nature, vol. 375, no. 6534, pp. 754-760, 1995.

[4] R. J. Bateman, P. S. Aisen, B. De Strooper et al., "Autosomaldominant Alzheimer's disease: a review and proposal for the prevention of Alzheimer's disease," Alzheimer's Research and Therapy, vol. 3, no. 1, article 1, 2011.

[5] R. J. Harvey, M. Skelton-Robinson, and M. N. Rossor, "The prevalence and causes of dementia in people under the age of 65 years," Journal of Neurology, Neurosurgery and Psychiatry, vol. 74, no. 9, pp. 1206-1209, 2003.

[6] C. Ikejima, F. Yasuno, K. Mizukami, M. Sasaki, S. Tanimukai, and T. Asada, "Prevalence and causes of early-onset dementia in japan: a population-based study," Stroke, vol. 40, no. 8, pp. 2709-2714, 2009.

[7] J. Garre-Olmo, D. Genís Batlle, M. Del Mar Fernández et al., "Incidence and subtypes of early-onset dementia in a geographically defined general population," Neurology, vol. 75, no. 14, pp. 1249-1255, 2010.

[8] O. Yokota, K. Sasaki, Y. Fujisawa et al., "Frequency of early and late-onset dementias in a Japanese memory disorders clinic," European Journal of Neurology, vol. 12, no. 10, pp. 782-790, 2005.

[9] L. Mercy, J. R. Hodges, K. Dawson, R. A. Barker, and C. Brayne, "Incidence of early-onset dementias in Cambridgeshire, United Kingdom," Neurology, vol. 71, no. 19, pp. 1496-1499, 2008.

[10] S. G. Papageorgiou, T. Kontaxis, A. Bonakis, N. Kalfakis, and D. Vassilopoulos, "Frequency and causes of early-onset dementia in a tertiary referral center in athens," Alzheimer Disease and Associated Disorders, vol. 23, no. 4, pp. 347-351, 2009.

[11] B. Borroni, A. Alberici, M. Grassi et al., "Prevalence and demographic features of early-onset neurodegenerative dementia in Brescia County, Italy," Alzheimer Disease and Associated Disorders, vol. 25, no. 4, pp. 341-344, 2011.

[12] D. Campion, C. Dumanchin, D. Hannequin et al., "Early-onset autosomal dominant Alzheimer disease: prevalence, genetic heterogeneity, and mutation spectrum," American Journal of Human Genetics, vol. 65, no. 3, pp. 664-670, 1999.

[13] M. Cruts, C. M. Van Duijn, H. Backhovens et al., "Estimation of the genetic contribution of presenilin-1 and -2 mutations 
in a population-based study of presenile Alzheimer disease," Human Molecular Genetics, vol. 7, no. 1, pp. 43-51, 1998.

[14] J. C. Janssen, J. A. Beck, T. A. Campbell et al., "Early onset familial Alzheimer's disease: mutation frequency in 31 families," Neurology, vol. 60, no. 2, pp. 235-239, 2003.

[15] G. Raux, L. Guyant-Maréchal, C. Martin et al., "Molecular diagnosis of autosomal dominant early onset Alzheimer's disease: an update," Journal of Medical Genetics, vol. 42, no. 10, pp. 793-795, 2005.

[16] K. Kasuga, T. Shimohata, A. Nishimura et al., "Identification of independent APP locus duplication in Japanese patients with early-onset Alzheimer disease," Journal of Neurology, Neurosurgery and Psychiatry, vol. 80, no. 9, pp. 1050-1052, 2009.

[17] K. Sleegers, N. Brouwers, I. Gijselinck et al., "APP duplication is sufficient to cause early onset Alzheimer's dementia with cerebral amyloid angiopathy," Brain, vol. 129, no. 11, pp. 29772983, 2006.

[18] E. S. Blom, J. Viswanathan, L. Kilander et al., "Low prevalence of APP duplications in Swedish and Finnish patients with early-onset Alzheimer's disease," European Journal of Human Genetics, vol. 16, no. 2, pp. 171-175, 2008.

[19] H. Braak and E. Braak, "Neuropathological stageing of Alzheimer-related changes," Acta Neuropathologica, vol. 82, no. 4, pp. 239-259, 1991.

[20] B. T. Hyman, "Amyloid-dependent and amyloid-independent stages of alzheimer disease," Archives of Neurology, vol. 68, no. 8, pp. 1062-1064, 2011.

[21] B. De Strooper, P. Saftig, K. Craessaerts et al., "Deficiency of presenilin-1 inhibits the normal cleavage of amyloid precursor protein," Nature, vol. 391, no. 6665, pp. 387-390, 1998.

[22] X. Cao and T. C. Sudhof, "A transcriptively active complex of APP with Fe65 and histone acetyltransferase Tip60," Science, vol. 293, no. 5534, pp. 115-120, 2001.

[23] R. Vassar, B. D. Bennett, S. Babu-Khan et al., “ $\beta$-Secretase cleavage of Alzheimer's amyloid precursor protein by the transmembrane aspartic protease BACE," Science, vol. 286, no. 5440, pp. 735-741, 1999.

[24] M. Citron, T. S. Diehl, G. Gordon, A. L. Biere, P. Seubert, and D. J. Selkoe, "Evidence that the 42- and 40-amino acid forms of amyloid $\beta$ protein are generated from the $\beta$-amyloid precursor protein by different protease activities," Proceedings of the National Academy of Sciences of the United States of America, vol. 93, no. 23, pp. 13170-13175, 1996.

[25] T. Tomiyama, T. Nagata, H. Shimada et al., "A new amyloid $\beta$ variant favoring oligomerization in Alzheimer's-type dementia," Annals of Neurology, vol. 63, no. 3, pp. 377-387, 2008.

[26] A. Tandon, E. Rogaeva, M. Mullan, and P. H. St. GeorgeHyslop, "Molecular genetics of Alzheimer's disease: the role of $\beta$-amyloid and the presenilins," Current Opinion in Neurology, vol. 13, no. 4, pp. 377-384, 2000.

[27] D. Edbauer, E. Winkler, J. T. Regula, B. Pesold, H. Steiner, and C. Haass, "Reconstitution of $\gamma$-secretase activity", Nature Cell Biology, vol. 5, no. 5, pp. 486-488, 2003.

[28] G. Di Fede, M. Catania, M. Morbin et al., "A recessive mutation in the APP gene with dominant-negative effect on amyloidogenesis," Science, vol. 323, no. 5920, pp. 1473-1477, 2009.

[29] C. Zekanowski and U. Wojda, "Aneuploidy, chromosomal missegregation, and cell cycle reentry in Alzheimer's disease," Acta Neurobiologiae Experimentalis, vol. 69, no. 2, pp. 232-253, 2009.
[30] A. Rovelet-Lecrux, D. Hannequin, G. Raux et al., "APP locus duplication causes autosomal dominant early-onset Alzheimer disease with cerebral amyloid angiopathy," Nature Genetics, vol. 38, no. 1, pp. 24-26, 2006.

[31] L. Cabrejo, L. Guyant-Maréchal, A. Laquerrière et al., "Phenotype associated with APP duplication in five families," Brain, vol. 129, no. 11, pp. 2966-2976, 2006.

[32] T. Jonsson, J. K. Atwal, S. Steinberg et al., "A mutation in APP protects against Alzheimer's disease and age-related cognitive decline," Nature, vol. 488, pp. 96-99, 2012.

[33] D. Scheuner, C. Eckman, M. Jensen et al., "Secreted amyloid $\beta$-protein similar to that in the senile plaques of Alzheimer's disease is increased in vivo by the presenilin 1 and 2 and APP mutations linked to familial Alzheimer's disease," Nature Medicine, vol. 2, no. 8, pp. 864-870, 1996.

[34] S. Kumar-Singh, J. Theuns, B. Van Broeck et al., "Mean ageof-onset of familial Alzheimer disease caused by presenilin mutations correlates with both increased $\mathrm{A} \beta 42$ and decreased

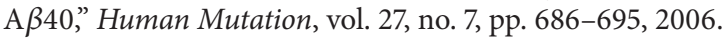

[35] M. Bentahir, O. Nyabi, J. Verhamme et al., "Presenilin clinical mutations can affect $\gamma$-secretase activity by different mechanisms," Journal of Neurochemistry, vol. 96, no. 3, pp. 732-742, 2006.

[36] A. J. Larner and M. Doran, "Clinical phenotypic heterogeneity of Alzheimer's disease associated with mutations of the presenilin-1 gene," Journal of Neurology, vol. 253, no. 2, pp. 139$158,2006$.

[37] A. J. Larner, "Presenilin-1 mutations in Alzheimer's disease: an update on genotype-phenotype relationships," Journal of Alzheimer's Disease, vol. 37, no. 4, pp. 653-659, 2013.

[38] W. T. Kimberly, M. J. LaVoie, B. L. Ostaszewski, W. Ye, M. S. Wolfe, and D. J. Selkoe, " $\gamma$-Secretase is a membrane protein complex comprised of presenilin, nicastrin, aph-1, and pen-2," Proceedings of the National Academy of Sciences of the United States of America, vol. 100, no. 11, pp. 6382-6387, 2003.

[39] M. H. Park, D. Y. Choi, H. W. Jin et al., "Mutant presenilin 2 increases $\beta$-secretase activity through reactive oxygen speciesdependent activation of extracellular signal-regulated kinase," Journal of Neuropathology and Experimental Neurology, vol. 71, no. 2, pp. 130-139, 2012.

[40] B. J. Snider, J. Norton, M. A. Coats et al., "Novel presenilin 1 mutation (S170F) causing Alzheimer disease with lewy bodies in the third decade of life," Archives of Neurology, vol. 62, no. 12, pp. 1821-1830, 2005.

[41] P. Pastor, C. M. Roe, A. Villegas et al., "Apolipoprotein E $\varepsilon 4$ modifies Alzheimer's disease onset in an E280A PS1 kindred," Annals of Neurology, vol. 54, no. 2, pp. 163-169, 2003.

[42] L. Bernardi, M. Gallo, M. Anfossi et al., "Role of TOMM40 rs10524523 polymorphism in onset of Alzheimer's disease caused by the PSEN1 M146L mutation," Journal of Alzheimer's Disease, vol. 37, pp. 285-289, 2013.

[43] T. D. Bird, E. Levy-Lahad, P. Poorkaj et al., "Wide range in age of onset for chromosome 1-related familial Alzheimer's disease," Annals of Neurology, vol. 40, no. 6, pp. 932-936, 1996.

[44] E. K. Warrington, S. K. Agnew, A. M. Kennedy, and M. N. Rossor, "Neuropsychological profiles of familial Alzheimer's disease associated with mutations in the presenilin 1 and amyloid precursor protein genes," Journal of Neurology, vol. 248, no. 1 , pp. 45-50, 2001.

[45] A. K. Godbolt, L. Cipolotti, H. Watt, N. C. Fox, J. C. Janssen, and M. N. Rossor, "The natural history of Alzheimer disease: 
a longitudinal presymptomatic and symptomatic study of a familial cohort," Archives of Neurology, vol. 61, no. 11, pp. 17431748, 2004.

[46] N. C. Fox, E. K. Warrington, A. L. Seiffer, S. K. Agnew, and M. N. Rossor, "Presymptomatic cognitive deficits in individuals at risk of familial Alzheimer's disease. A longitudinal prospective study," Brain, vol. 121, no. 9, pp. 1631-1639, 1998.

[47] R. J. Bateman, C. Xiong, T. L. Benzinger et al., "Clinical and biomarker changes in dominantly inherited Alzheimer's disease," The New England Journal of Medicine, vol. 367, pp. 795804, 2012.

[48] A. Ardila, F. Lopera, M. Rosselli et al., "Neuropsychological profile of a large kindred with familial Alzheimer's disease caused by the E280A single presenilin-1 mutation," Archives of Clinical Neuropsychology, vol. 15, no. 6, pp. 515-528, 2000.

[49] A. Jimenez-Escrig, A. Rabano, C. Guerrero et al., "New V272A presenilin 1 mutation with very early onset subcortical dementia and parkinsonism," European Journal of Neurology, vol. 11, no. 10, pp. 663-669, 2004.

[50] E. J. Sitek, E. Narozanska, B. Peplonska et al., "A patient with posterior cortical atrophy possesses a novel mutation in the presenilin 1 gene," PloS ONE, vol. 8, Article ID e61074, 2013.

[51] B. Borroni, A. Pilotto, C. Bonvicini et al., "Atypical presentation of a novel Presenilin 1 R377W mutation: sporadic, late-onset Alzheimer disease with epilepsy and frontotemporal atrophy," Neurological Sciences, vol. 33, no. 2, pp. 375-378, 2012.

[52] H. Watanabe, D. Xia, T. Kanekiyo, R. J. Kelleher, and J. Shen, "Familial frontotemporal dementia-associated Presenilin-1 c.548G $>\mathrm{T}$ mutation causes decreased mRNA expression and reduced presenilin function in knock-in mice," Journal of Neuroscience, vol. 32, no. 15, pp. 5085-5096, 2012.

[53] A. Padovani, E. Premi, A. Pilotto et al., "Overlap between frontotemporal dementia and Alzheimer's disease: cerebrospinal fluid pattern and neuroimaging study," Journal of Alzheimer's Disease, vol. 36, pp. 49-55, 2013.

[54] D. Sepulveda-Falla, M. Glatzel, and F. Lopera, "Phenotypic profile of early-onset familial Alzheimer's disease caused by presenilin-1 E280A mutation," Journal of Alzheimer's Disease, vol. 32, pp. 1-12, 2012.

[55] A. Alberici, C. Bonato, B. Borroni et al., "Dementia, delusions and seizures: storage disease or genetic AD?" European Journal of Neurology, vol. 14, no. 9, pp. 1057-1059, 2007.

[56] A. J. Larner, "Presenilin-1 mutation Alzheimer's disease: a genetic epilepsy syndrome?" Epilepsy and Behavior, vol. 21, no. 1, pp. 20-22, 2011.

[57] R. Minkeviciene, S. Rheims, M. B. Dobszay et al., "Amyloid $\beta$-induced neuronal hyperexcitability triggers progressive epilepsy," Journal of Neuroscience, vol. 29, no. 11, pp. 3453-3462, 2009.

[58] A. Ishikawa, Y.-S. Piao, A. Miyashita et al., "A mutant PSEN1 causes dementia with Lewy bodies and variant Alzheimer's disease," Annals of Neurology, vol. 57, no. 3, pp. 429-434, 2005.

[59] P. Piscopo, G. Marcon, M. R. Piras et al., "A novel PSEN2 mutation associated with a peculiar phenotype," Neurology, vol. 70, no. 17, pp. 1549-1554, 2008.

[60] H. Karlstrom, W. S. Brooks, J. B. J. Kwok et al., "Variable phenotype of Alzheimer's disease with spastic paraparesis," Journal of Neurochemistry, vol. 104, no. 3, pp. 573-583, 2008.

[61] A. Verkkoniemi, M. Somer, J. O. Rinne et al., "Variant Alzheimer's disease with spastic paraparesis: clinical characterization," Neurology, vol. 54, no. 5, pp. 1103-1109, 2000.
[62] T. Revesz, J. L. Holton, T. Lashley et al., "Sporadic and familial cerebral amyloid angiopathies," Brain Pathology, vol. 12, no. 3, pp. 343-357, 2002.

[63] R. J. Ellis, J. M. Olichney, L. J. Thal et al., "Cerebral amyloid angiopathy in the brains of patients with Alzheimer's disease: the CERAD experience, part XV,' Neurology, vol. 46, no. 6, pp. 1592-1596, 1996.

[64] E. Levy, M. D. Carman, I. J. Fernandez-Madrid et al., "Mutation of the Alzheimer's disease amyloid gene in hereditary cerebral hemorrhage, Dutch type," Science, vol. 248, no. 4959, pp. 11241126, 1990.

[65] M. Bornebroek, J. Haan, M. L. C. Maat-Schieman, S. G. Van Duinen, and R. A. C. Roos, "Hereditary cerebral hemorrhage with amyloidosis-Dutch type (HCHWA-D): I-a review of clinical, radiologic and genetic aspects," Brain Pathology, vol. 6, no. 2, pp. 111-114, 1996.

[66] B. F. Jones, J. Barnes, H. B. M. Uylings et al., "Differential regional atrophy of the cingulate gyrus in Alzheimer disease: a volumetric MRI study," Cerebral Cortex, vol. 16, no. 12, pp. 17011708, 2006.

[67] N. C. Fox, W. R. Crum, R. I. Scahill, J. M. Stevens, J. C. Janssen, and M. N. Rossor, "Imaging of onset and progression of Alzheimer's disease with voxel-compression mapping of serial magnetic resonance images," The Lancet, vol. 358, no. 9277, pp. 201-205, 2001.

[68] G. C. Gregory, V. Macdonald, P. R. Schofield, J. J. Kril, and G. M. Halliday, "Differences in regional brain atrophy in genetic forms of Alzheimer's disease," Neurobiology of Aging, vol. 27, no. 3, pp. 387-393, 2006.

[69] A. Ginestroni, M. Battaglini, R. Della Nave et al., "Early structural changes in individuals at risk of familial Alzheimer's disease: a volumetry and magnetization transfer MR imaging study," Journal of Neurology, vol. 256, no. 6, pp. 925-932, 2009.

[70] G. B. Frisoni, M. Pievani, C. Testa et al., "The topography of grey matter involvement in early and late onset Alzheimer's disease," Brain, vol. 130, no. 3, pp. 720-730, 2007.

[71] L. G. Apostolova, K. S. Hwang, L. D. Medina et al., "Cortical and hippocampal atrophy in patients with autosomal dominant familial Alzheimer's disease," Dementia and Geriatric Cognitive Disorders, vol. 32, no. 2, pp. 118-125, 2011.

[72] R. I. Scahill, G. R. Ridgway, J. W. Bartlett et al., "Genetic influences on atrophy patterns in familial Alzheimer's Disease: a comparison of APP and PSEN1 mutations," Journal of Alzheimer's Disease, vol. 35, pp. 199-212, 2013.

[73] P. B. Gorelick, A. Scuteri, S. E. Black et al., "Vascular contributions to cognitive impairment and dementia: a statement for healthcare professionals from the American Heart Association/American Stroke Association," Stroke, vol. 42, no. 9, pp. 2672-2713, 2011.

[74] F. Fazekas, R. Kleinert, G. Roob et al., "Histopathologic analysis of foci of signal loss on gradient-echo $\mathrm{T} 2{ }^{*}$-weighted MR images in patients with spontaneous intracerebral hemorrhage: evidence of microangiopathy-related microbleeds," American Journal of Neuroradiology, vol. 20, no. 4, pp. 637-642, 1999.

[75] E. M. Haacke, Z. S. DelProposto, S. Chaturvedi et al., "Imaging cerebral amyloid angiopathy with susceptibility-weighted imaging," American Journal of Neuroradiology, vol. 28, no. 2, pp. 316317, 2007.

[76] S. M. Greenberg, M. W. Vernooij, C. Cordonnier et al., "Cerebral microbleeds: a guide to detection and interpretation," The Lancet Neurology, vol. 8, no. 2, pp. 165-174, 2009. 
[77] S. D. Friedman, D. W. W. Shaw, G. Ishak, A. L. Gropman, and R. P. Saneto, "The use of neuroimaging in the diagnosis of mitochondrial disease," Developmental Disabilities Research Reviews, vol. 16, no. 2, pp. 129-135, 2010.

[78] I. Zerr, K. Kallenberg, D. M. Summers et al., "Updated clinical diagnostic criteria for sporadic Creutzfeldt-Jakob disease," Brain, vol. 132, pp. 2659-2668, 2009.

[79] T. Autti, R. Joensuu, and L. Åberg, "Decreased T2 signal in the thalami may be a sign of lysosomal storage disease," Neuroradiology, vol. 49, no. 7, pp. 571-578, 2007.

[80] N. I. Bohnen, D. S. W. Djang, K. Herholz, Y. Anzai, and S. Minoshima, "Effectiveness and safety of ${ }^{18}$ F-FDG PET in the evaluation of dementia: a review of the recent literature," Journal of Nuclear Medicine, vol. 53, no. 1, pp. 59-71, 2012.

[81] K. Herholz, H. Schopphoff, M. Schmidt et al., "Direct comparison of spatially normalized PET and SPECT scans in Alzheimer's disease," Journal of Nuclear Medicine, vol. 43, no. 1, pp. 21-26, 2002.

[82] T. Nihashi, H. Yatsuya, K. Hayasaka et al., "Direct comparison study between FDG-PET and IMP-SPECT for diagnosing Alzheimer's disease using 3D-SSP analysis in the same patients," Radiation Medicine, vol. 25, no. 6, pp. 255-262, 2007.

[83] V. L. Villemagne, S. Ataka, T. Mizuno et al., "High striatal amyloid $\beta$-peptide deposition across different autosomal Alzheimer disease mutation types," Archives of Neurology, vol. 66, no. 12, pp. 1537-1544, 2009.

[84] K. Herholz and K. Ebmeier, "Clinical amyloid imaging in Alzheimer's disease," The Lancet Neurology, vol. 10, no. 7, pp. 667-670, 2011.

[85] G. D. Rabinovici, H. J. Rosen, A. Alkalay et al., "Amyloid vs FDG-PET in the differential diagnosis of AD and FTLD," Neurology, vol. 77, no. 23, pp. 2034-2042, 2011.

[86] W. Maetzler, I. Liepelt, M. Reimold et al., "Cortical PIB binding in Lewy body disease is associated with Alzheimer-like characteristics," Neurobiology of Disease, vol. 34, no. 1, pp. 107112, 2009.

[87] C. E. Leyton, V. L. Villemagne, S. Savage et al., "Subtypes of progressive aphasia: application of the international consensus criteria and validation using $\beta$-amyloid imaging," Brain, vol. 134, no. 10, pp. 3030-3043, 2011.

[88] J. M. Ringman, S. G. Younkin, D. Pratico et al., "Biochemical markers in persons with preclinical familial Alzheimer disease," Neurology, vol. 71, no. 2, pp. 85-92, 2008.

[89] L. M. Shaw, H. Vanderstichele, M. Knapik-Czajka et al., "Cerebrospinal fluid biomarker signature in alzheimer's disease neuroimaging initiative subjects," Annals of Neurology, vol. 65, no. 4, pp. 403-413, 2009.

[90] A. M. Fagan, M. A. Mintun, R. H. Mach et al., "Inverse relation between in vivo amyloid imaging load and cerebrospinal fluid Abeta;42 in humans," Annals of Neurology, vol. 59, no. 3, pp. 512519, 2006.

[91] E. M. Reiman, Y. T. Quiroz, A. S. Fleisher et al., "Brain imaging and fluid biomarker analysis in young adults at genetic risk for autosomal dominant Alzheimer's disease in the presenilin 1 E280A kindred: a case-control study," The Lancet Neurology, vol. 11, pp. 1048-1056, 2012.

[92] B. Borroni, E. Premi, C. Agosti et al., "CSF Alzheimer's diseaselike pattern in corticobasal syndrome: evidence for a distinct disorder," Journal of Neurology, Neurosurgery and Psychiatry, vol. 82, no. 8, pp. 834-838, 2011.
[93] A. Kas, O. Uspenskaya, F. Lamari et al., "Distinct brain perfusion pattern associated with CSF biomarkers profile in primary progressive aphasia," Journal of Neurology, Neurosurgery, and Psychiatry, vol. 83, pp. 695-698, 2012.

[94] K. Blennow, H. Hampel, M. Weiner, and H. Zetterberg, "Cerebrospinal fluid and plasma biomarkers in Alzheimer disease," Nature Reviews Neurology, vol. 6, no. 3, pp. 131-144, 2010.

[95] J. Beck, A. Pittman, G. Adamson et al., "Validation of nextgeneration sequencing technologies in genetic diagnosis of dementia," Neurobiol Aging, vol. 35, no. 1, pp. 261-265, 2014.

[96] A. Antonell, A. Lladó, J. Altirriba et al., "A preliminary study of the whole-genome expression profile of sporadic and monogenic early-onset Alzheimer's disease," Neurobiol Aging, vol. 34, no. 7, pp. 1772-1778, 2013.

[97] E. Milanesi, C. Bonvicini, A. Alberici et al., "Molecular signature of disease onset in Granulin mutation carriers: a gene expression analysis study," Neurobiol Aging, vol. 34, no. 7, pp. 18371845, 2013.

[98] A. S. Fleisher, K. Chen, Y. T. Quiroz et al., "Florbetapir PET analysis of amyloid-beta deposition in the presenilin 1 E280A autosomal dominant Alzheimer's disease kindred: a crosssectional study," The Lancet Neurology, vol. 11, pp. 1057-1065, 2012.

[99] J. M. Ringman, J. O’Neill, D. Geschwind et al., "Diffusion tensor imaging in preclinical and presymptomatic carriers of familial Alzheimer's disease mutations," Brain, vol. 130, no. 7, pp. $1767-$ 1776, 2007.

[100] G. J. Lee, P. H. Lu, L. D. Medina et al., "Regional brain volume differences in symptomatic and presymptomatic carriers of familial Alzheimer's disease mutations," Journal of Neurology, Neurosurgery, and Psychiatry, vol. 84, pp. 154-162, 2013.

[101] N. S. Ryan, S. Keihaninejad, T. J. Shakespeare et al., "Magnetic resonance imaging evidence for presymptomatic change in thalamus and caudate in familial Alzheimer's disease," Brain, vol. 136, pp. 1399-1414, 2013.

[102] Y. T. Quiroz, C. E. Stern, E. M. Reiman et al., "Cortical atrophy in presymptomatic Alzheimer's disease presenilin 1 mutation carriers," Journal of Neurology, Neurosurgery, and Psychiatry, vol. 84, pp. 556-561, 2013.

[103] D. Cash, G. Ridgway, Y. Liang et al., "On behalf of the Dominantly Inherited Alzheimer Network (DIAN). The pattern of atrophy in familial alzheimer disease: volumetric MRI results from the DIAN Study," Neurology, vol. 81, no. 16, pp. 1425-1433, 2013.

[104] J. P. Chhatwal, A. P. Schultz, K. Johnson et al., "Impaired default network functional connectivity in autosomal dominant Alzheimer disease," Neurology, vol. 81, pp. 736-744, 2013.

[105] B. Dubois, H. H. Feldman, C. Jacova et al., "Revising the definition of Alzheimer's disease: a new lexicon," The Lancet Neurology, vol. 9, no. 11, pp. 1118-1127, 2010. 


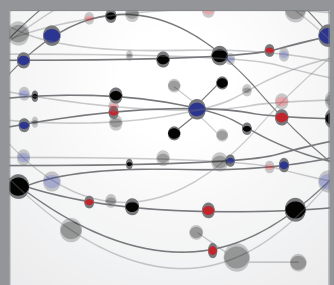

The Scientific World Journal
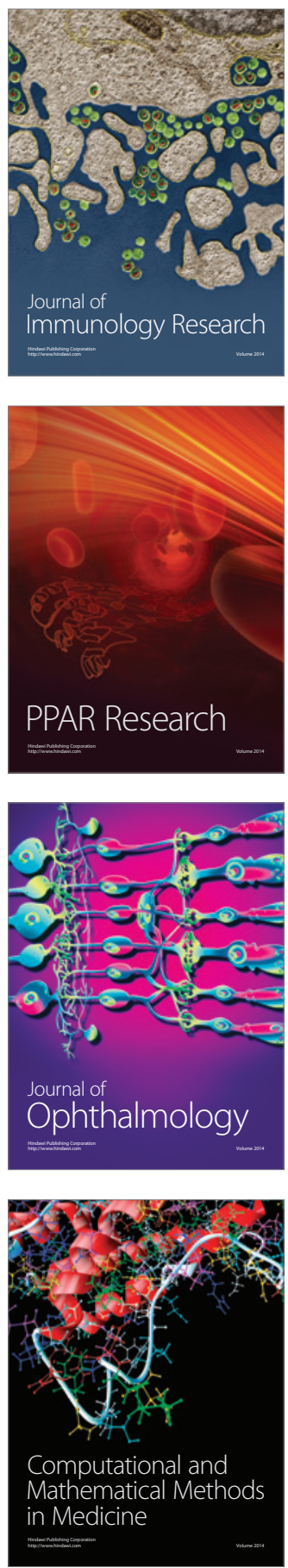

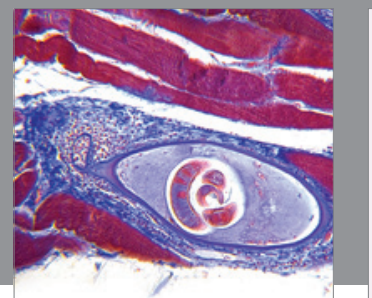

Gastroenterology

Research and Practice
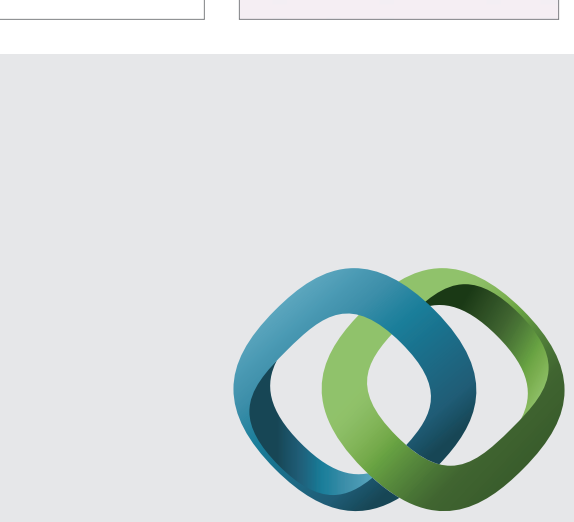

\section{Hindawi}

Submit your manuscripts at

http://www.hindawi.com
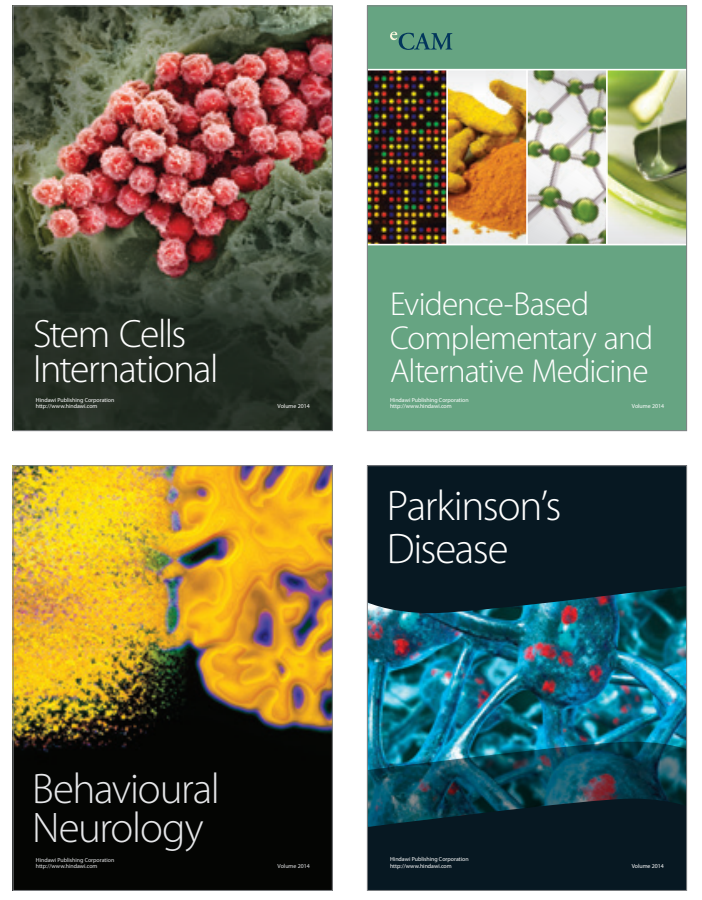
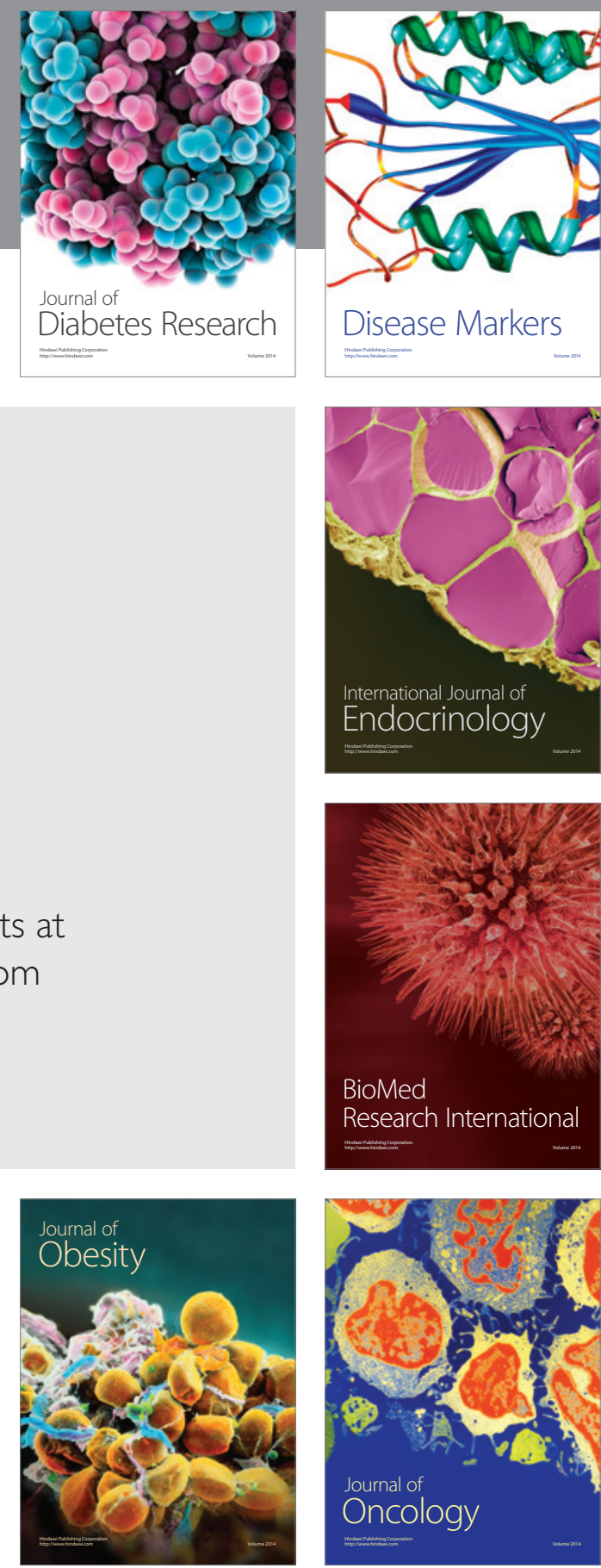

Disease Markers
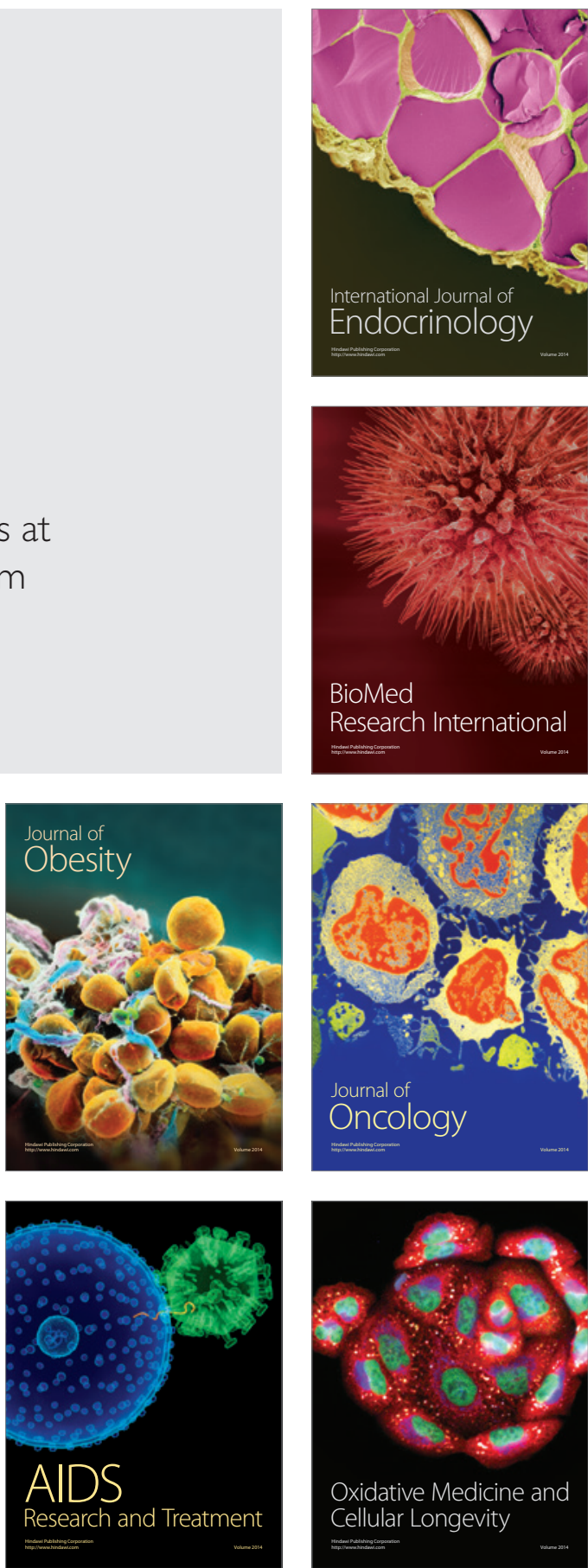